$(F=6.44, \quad$ df $=1 / 26, \quad p<.05)$. The interaction was not reliable, indicating that the two effects were relatively independent; for both body weights, the $50 \%$ animals ran faster during satiation than did the $100 \%$ animals.

Figure 1 also indicates that starting speeds were not constant during the satiation phase $(F=12.17, \mathrm{df}=11 / 286$, $\mathrm{p}<.01)$. This change over trials occurs primarily during the first two satiation sessions. However, the decrement does not seem attributable to increasingly effective satiation since it occurred largely within each session.

During the satiation phase, food reward was continued in the goalbox. Despite free access to such a reward immediately prior to each daily session, Ss continued to consume the goalbox reward with infrequent exceptions.

\section{DISCUSSION}

The finding of primary interest in this study is that partially reinforced animals are more resistant to the decremental effects of satiation than are continuously reinforced animals. Linton \& Miller (1951), in an experiment similar to ours, also found a tendency for greater persistence of intermittently reinforced animals when satiated. Since the difference in their experiment was not statistically reliable, they concluded that percentage reinforcement had no effect upon subsequent behavior under satiation; however, reliable differences among their groups prior to satiation make interpretation of their results difficult.

The present findings, taken together with the higher resistance of partially reinforced animals to the effects of extinction and punishment, suggest the possibility that intermittent reinforcement yields a response of greater stability in the face of any interfering events. In addition to whatever other effects partial reinforcement may have, it may generate greater "response strength." Should this prove so, it would have implications for theories of the partial-reinforcement extinction effect. For instance, it is difficult to argue that the resistance to the effects of satiation in partially reinforced animals is mediated by the similarity in the aversive consequences of nonreinforcement and satiation.

The faster starting speeds of animals with a history of more severe deprivation may be interpreted in terms of the effects of drive upon amount of learning. However, some caution should be exercised in making this interpretation. During satiation, the average body weight of the $80 \%$ groups remained below that of the $90 \%$ groups, suggesting that satiation may have been less complete for those animals.

\section{REFERENCES}

AMSEL, A. Behavioral habjtuation, counterconditioning, and persistence. Presented at a conference on classical conditioning, McMaster University, May 1969. BROWN, R. T., \& WAGNER, A. R. Resistance to punishment and extinction following training with shock or nonreinforcement. Journal of Experimental Psychology, 1964, 68, 503-507. LINTON, H. B., \& MILLER, N. E. The effect of partial reinforcement on behavior during satiation. Joumal of Comparative \& Physiological Psychology, 1951, 44, 142-148. NOTE

1. This research was supported in part by NSF Grant GB-6493 and in part by funds from Yale University. The first three authors were undergraduates supervised by the last author. Reprint requests should be sent to: Robert $A$. Rescorla, Department of Psychology, Yale University, 333 Cedar St., New Haven, Conn. 06510.

\title{
Predictability of schedule-induced drink durations
}

\section{J. D. KEEHN and V. A. COLOTLA, York University and Addiction Research Foundation, Toronto, Ont., Canada}

Four white rats were reinforced with food for bar-pressing on fixed- and variable-interval schedules of 1 and $2 \mathrm{~min}$. All four developed polydipsia. Except for some disruption following schedule changes from variable to fixed intervals, licking almost invariably followed reinforcement. Cumulative plots of post-pellet drink durations closely approximated straight lines, showing drink durations to be relatively constant.

When food and water are freely available, the durations and distributions of eating and drinking by rats appear to be unpredictable (Premack, 1965). It is possible to alter average durations of bursts of eating (Premack, 1965) and drinking (Davis \& Keehn, 1959) by manipulating the quality of the substance offered for ingestion, but the unpredictability of the durations of individual consummatory response bursts remains unaffected. A way of affecting the predictability of individual bursts of licking without constraining drinking by either deprivation or contingencies may be to schedule small meals intermittently. Such a procedure produces polydipsia (Falk, 1961), in which unscheduled and unconstrained drinking typically follows food pellet consumption. There are indications (e.g., Falk, 1966) that the durations of drinks of this kind are relatively constant. Further evidence that induced postpellet drink durations may be predictable is reported below.

$$
\text { SUBJECTS }
$$

The Ss were four experimentally naive laboratory-bred hooded rats. They were about 150 days old at the beginning of the experiment and were maintained at $85 \%$ of their free-feeding body weights throughout the experiment. They were individually housed, and water was continuously available.

\section{APPARATUS}

Two Grason-Stadler two-bar rat chambers, Type E3125B, were employed. In each, the left-hand bar was removed and its opening covered with a metal plate flush with the wall. A dead weight of $20 \mathrm{~g}$ on the right-hand bar activated relay programming and recording equipment. Reinforcements were $45-\mathrm{mg}$ Noyes rat pellets delivered by a Gerbrands pellet dispenser. A Grason-Stadler drinkometer was used to monitor licks at the glass drinking spout of a water bottle clipped to the outside of the chamber door. Licks and bar-presses were recorded by Gerbrands cumulative recorders. The animal chambers were enclosed by ventilated chests in a closet of the room containing the cumulative recorders and electromagnetic programming apparatus.

Table 1

Median Water Intakes (ml Per 3 H Session)

\begin{tabular}{lrrrrr}
\hline \multicolumn{2}{l}{ Schedule* Sessions } & MD3 & MD4 & MD7 & MD8 \\
\hline VI & $1-23$ & 48 & 62 & 37 & 37 \\
FI** & $24-33$ & $35 * * *$ & 50 & 18 & 26 \\
VI** & $34-38$ & 34 & 46 & 41 & 37 \\
VI & $39-44$ & 42 & 58 & 59 & 46 \\
FI & $45-54$ & 38 & 44 & 56 & 45 \\
VI & $55-60$ & 42 & 72 & 69 & 45 \\
\hline
\end{tabular}

* Intervals were 1 min for $M D 3, M D 4, M D 7$; $2 \min$ for $M D 8$

** Sessions began with 50 crf in these periods *** The schedule for MD3 was VI in this period 


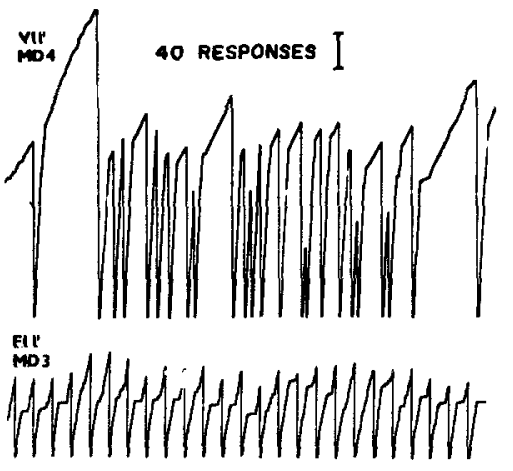

Fig. 1. Sample cumulative licking and bar-pressing records. Licks are the high-rate responses immediately after reinforcements. Recorder pen reset at reinforcement delivery.

\section{PROCEDURE}

After a few sessions of irregular lengths in which bar pressing was shaped and maintained, first with continuous reinforcement and then with reinforcements programmed at variable intervals averaging either $15 \mathrm{sec}$ or $30 \mathrm{sec}$, session lengths were stabilized at $3 \mathrm{~h}$ long. Then reinforcements were scheduled at fixed or variable intervals of $1 \mathrm{~min}$ (MD3, MD4, MD7) or $2 \min$ (MD8) in successive experimental periods, as shown in Table 1. Cumulative records of bar presses and licks were collected on every session, along with measures of session fluid intake.

\section{RESULTS AND DISCUSSION}

Median water intakes of each of the animals during each of the experimental periods are shown in Table 1. All four Ss consumed more water per session than normal daily water intakes of animals from the same colony (Matsunaga \& Keehn, 1969), and most drinking occurred immediately after reinforcement consumption, as shown by the sample cumulative response records in Fig. 1. These records contain both licking and bar-pressing responses, but it is easy to differentiate between them because of the higher rate of licking and the localization of drinking to periods immediately after reinforcement.

All animals showed some disruption of postpellet drinking on schedule changes from variable to fixed intervals of reinforcement, particularly at the end of a session, as shown in Fig. 2. Such disruption was transitory and the animals generally drank after almost all the pellets they consumed.

There are indications in Fig. 1 that postpellet drink durations might not be entirely random, but the degree of predictability of successive durations cannot be clearly discerned from the figure. Figure 3 is a clearer graphic presentation of postpellet drink durations. The records in the figure were constructed manually by accumulating the number of licks at the drinking tube following successive pellet deliveries. Apart from some examples of elevated drink durations at the very beginning of a session (cf. Falk, 1966), the cumulative records are close approximations to straight lines, indicating that postpellet drinks are of relatively constant duration for a particular animal, and therefore to a large degree predictable.

It appears, then, that durations of individual bursts of unconstrained and
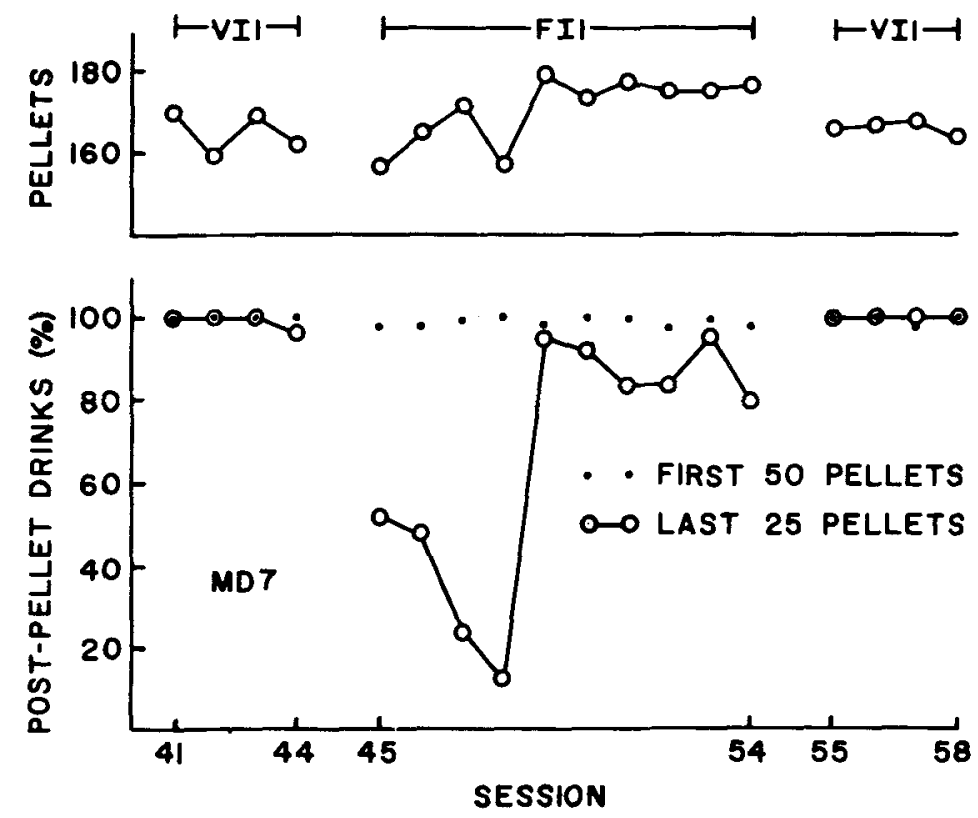

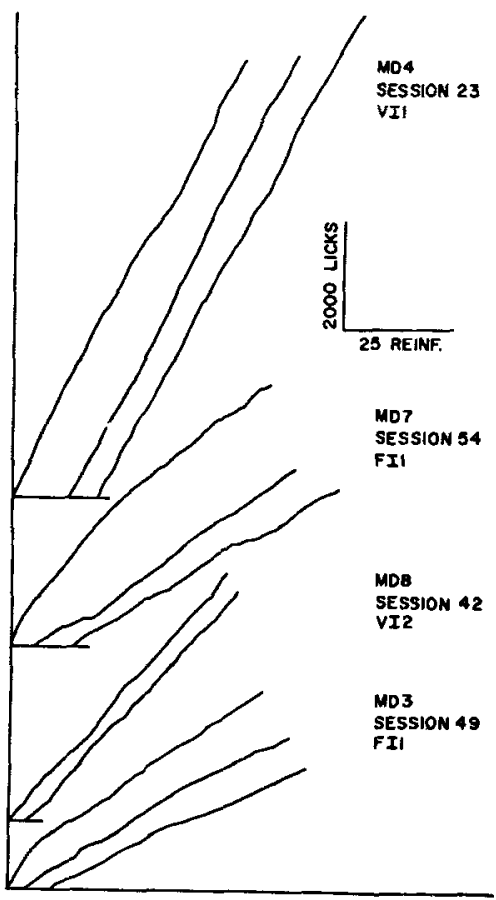

Fig. 3. Cumulative post-pellet lick burst durations.

uncontingent drinking can be brought to order by means of a controlled schedule of feeding. Whether or not drink durations can be controlled as well as predicted is another matter. Increasing meal sizes (Falk, 1967) and reducing palatability (Falk, 1966) apparently disrupt the consistency of postpellet drinking and eliminate drink duration predictability.

\section{REFERENCES}

DAVIS, J. D., \& KEEHN, J. D. Magnitude of reinforcement and consummatory behavior. Science, 1959, 130, 269-271.

FALK, J. L. Production of polydipsia in normal rats by an intermittent food schedule. Science, 1961, 133, 195-196.

FALK, J. L. Analysis of water and $\mathrm{NaCl}$ solution acceptance by schedule-induced polydipsia. Journal of the Experimental Analysis of Behavior, 1966, 9, 111-118.

FALK, J. L. Control of schedule-induced polydipsia: Type, size, and spacing of meals. Journal of the Experimental Analysis of Behavior, 1967, 10, 199-206.

MATSUNAGA, M., \& KEEHN, J. D. Attenuation of palatability-induced polydipsia by biperiden hydrochloride. Psychonomic Science, 1969, 17, 9-10.

PREMACK, D. Reinforcement theory. In D. Levine (Ed.), Nebraska symposium on motivation, 1965. Lincoln: University of Nebraska Press, 1965. Pp. 123-180.

Fig. 2. Pellets received and per cent drinks after the first $\mathbf{5 0}$ and the last $\mathbf{2 5}$ pellets under FI 1 and VI 1 reinforcement schedules. Curves of MD3 and MD4 are similar. 